\title{
Restless farewell
}

\author{
Loreto Carmona ${ }^{1}$
}

Received: 24 August 2017 / Accepted: 31 August 2017 / Published online: 5 September 2017

(C) Springer-Verlag GmbH Germany 2017

\section{"It's closing time/So I'll bid farewell and be down the road" [1].}

In 2013, I was appointed Editor-in-Chief of this journal. What I have learnt, what my team and I have achieved, I can only applaud and congratulate, and I am heartily grateful to Springer and Prof. Lemmel, Editor emeritus of this journal, for having thought of this Spanish woman, of whom many say she thinks out of the box, to run the journal.

You might have not noticed some changes in the journal, despite some not being small. The scope changed, in an attempt to reduce the amount of studies related to laboratory science-for which there are many journals better suited - and to increase the amount of papers on disciplines related to rheumatology but not so well taken care of in other rheumatology journals. I am referring to physical therapy, psychology or ophthalmology, among others. We made an additional effort to reach out for papers on medical and patient education and on public health issues, all of which are in need of a target journal in rheumatology, but we were not as successful. On the other hand, the journal has increasingly become a successful target for validation and genetic studies in the field of rheumatic diseases.

Other changes were behind the scenes, more in relation to processes. Editorial systems are becoming increasingly sophisticated, making submission more difficult rather than easier. Each journal has a different procedure, a different reference style, and different structure, making the journey towards a publication harder than it should be. We tried to facilitate some instructions by creating templates,

Loreto Carmona

loreto.carmona@inmusc.eu

1 Instituto de Salud Musculoesquelética, Calle Conde de la Cimera, 6, 28040 Madrid, Spain downloadable at the submission webpage. Also, changing the typical classification of papers and reviewers, usually based on a roll-down menu of diseases, into a more elaborated form based on disease, but also specialty, methodology, and other aspects, has facilitated the work of both authors and editors. Nevertheless, there is still plenty of room to improve. Perhaps, it would be the time for rheumatology journals to establish together certain submission rules, so that it does not take longer to prepare the documents than to prepare the actual report. We will see, "couse the times... they are-a changing".

Plagiarism [2,3] and ghost authorship [4] have been two of our battles as editors in these years; battles that I knew were to be mine when I enthusiastically started 4 years ago [5]. As I said at that time, "We rush to study, we rush to work, we rush to collect data-almost forgetting to write a protocol first - we rush to submit our data to a thousand congresses, to get them published. That is not the way to go. Why race to publication whatever it takes?" I am afraid things have not improved massively. On the contrary, we now have processes and tools like Ithenticate that have been incorporated into the editors' routine to at least identify plagiarism, but we have not gone against the root of the problem. "Academicitis" and "publicationitis" are two modern epidemics among researchers and either we find new quality indicators other than impact factor, or we will not be able to find truly worthy research. I have faith in Homo sapiens despite all crazy things happening in our world today that are inevitably harming science as well as most other aspects of life.

The other day I was discussing with my husband, also a scientist, about how odd it is to find a well-written manuscript-mine included, of course! English is perhaps the greatest obstacle to many a scientist without resources; English is not the first tongue to most authors submitting 
to this and to other journals. Some manuscripts come just unreadable despite great ideas and probably correctly done studies and we have to reject them with a heartache. This is an advantage English-speaking authors and reviewers do not value strongly enough. There should be a system implemented freely to correct manuscripts as you write or as you submit, proposing better expressions, i.e. more scientific expressions. We cannot publish poorly written manuscripts; we have to write the best we can to make our research understandable. Many editing services have proliferated, which is not ideal, but the best solution so far. The proposal of my husband was crazier, but far more equitable: if Latin were the science language and not English, we would all have the same barrier. I could not but laugh at the idea.

Being an editor is not an easy undertaking. An editor has no holidays, not the usual ones when one disconnects totally from work. Every day a journal gets submissions, regardless where you are, or what you are doing; submission never stops: a congress, a course, or a working trip. When you come back the list is unsurmountable. Authors are eager to know the result, which is not what they expected $70 \%$ of the time. I could not feel other than wrecked at times; late rejects are a twisted feeling, even to editors, not only to authors. But the pace is hard. It may not be as hard if you do not have a full-time job on top of the editorship - or several as is my circumstance-but in that case you are seldom appointed an editor.

With up and downs, with lights and shadows, I have done my best and hope you as reader, or as author, or as reviewer, have felt I took it seriously. I thank my associate editors and infinitely thank the reviewers, authors, Springer people, and Concha, my secretarial help with the journal. "This is me,
I've done my best, and that's all I can do for that's how I am" [1]. I wish you the best, next Editor-in-Chief.

\section{Compliance with ethical standards}

Considering the nature of the manuscript, an editorial, no research was undertaken. The writer is responsible solely for the integrity of the work.

Conflict of interest None.

Funding No funding.

Ethical approval This article does not contain any studies with human participants or animals performed by any of the authors.

Informed consent Not applicable.

\section{References}

1. Dylan B (1964) Restless farewell. In: Times they are a changing (Music album). Columbia Records

2. Luksanapruksa P, Millhouse PW (2016) Guidelines on what constitutes plagiarism and electronic tools to detect it. Clin Spine Surg 29(3):119-120. doi:10.1097/BSD.0000000000000371

3. Nasiri S, Karimifar M, Bonakdar ZS, Salesi M (2016) Retraction Note to: correlation of ESR, C3, C4, anti-DNA and lupus activity based on British Isles Lupus Assessment Group Index in patients of rheumatology clinic. Rheumatol Int 36(5):749. doi:10.1007/ s00296-016-3471-x

4. Moots RJ, Wilson K, Silverman ED, International Rheumatology E (2016) Ghost busting, taking the sheet off the ghost. Rheumatol Int 36(4):455-456. doi:10.1007/s00296-016-3439-x

5. Carmona L (2013) A full new enthusiastic team. Rheumatol Int $33: 825-826$ 